\title{
Interocular biometric parameters comparison measured with swept-source technology
}

\author{
César Albarrán-Diego • Francisco Poyales • Esther López-Artero • \\ Nuria Garzón (10) María García-Montero
}

Received: 7 December 2020/Accepted: 14 August 2021/Published online: 21 August 2021

(C) The Author(s) 2021

\begin{abstract}
Purpose In the event that any ocular parameter involved in the calculation of intraocular lens power could not be properly measured in one eye, it is important to know whether clinically relevant differences between both eyes can be expected. The aim of this work is to evaluate the symmetry of interocular biometric parameters.

Methods This was a prospective, cross-sectional study involving 4090 subjects. Patients underwent consecutive swept-source optical biometry performed with an IOLMaster 700 (Carl Zeiss Meditec AG, Jena, Germany). The biometric parameters that were evaluated were: axial length (AL), mean anterior curvature $(\mathrm{Rm})$, anterior chamber depth (ACD), crystalline lens thickness (LT), central corneal thickness (CCT) and white-to-white (WTW). The Chang-Waring chord distance (CWC-D) and the Chang-Waring chord angle (CWC-A) were also evaluated.
\end{abstract}

C. Albarrán-Diego

Optics, Optometry and Vision Science Department, Faculty of Physics, University of Valencia, Dr Moliner 50, 46100 Burjassot, Spain

F. Poyales · E. López-Artero · N. Garzón

Miranza OA Madrid. C/Galileo 104, 28003 Madrid, Spain

N. Garzón $(\bowtie) \cdot$ M. García-Montero

Faculty of Optics and Optometry, Complutense University of Madrid, c/Arcos de Jalón, 118, 28037 Madrid, Spain

e-mail: nugarzon@opt.ucm.es
Results There is an excellent correlation between both eyes for almost all the biometric parameters under study, with the exception of the CWC. Agreement for AL was better for eyes shorter than $24 \mathrm{~mm}$. The linearity of the OD-vs-OS relationship can be correctly assumed for all parameters (Cusum test: $p>0.05$ in all cases).

Conclusion There are no clinically significant interocular differences for the biometric parameters under study, although for all of them, except the LT, statistically significant differences did arise. In the case of AL, moderate differences can be expected in eyes larger than $24 \mathrm{~mm}$.

Keywords Interocular symmetry $\cdot$ Swept-source . Biometry · IOLMaster 700

\section{Introduction}

Numerous ocular symmetry assessment studies have been carried out, concluding that two eyes follow similar patterns regarding several ocular parameters [1-5]. Therefore, we can say that structural symmetry is inherent to both eyes [2]. This ocular symmetry can aid the diagnosis of pathologies, but it could also help to improve postoperative outcomes, among other scenarios. For example, in LASIK refractive surgery or cataract surgery, several studies have concluded 
that postoperative refraction in the first eye can help predict refraction outcomes in the second eye [5-8].

Ocular biometry is an essential part of preoperative assessment when evaluating a patient undergoing lens replacement surgery. The latest-generation formulas have included an increasing number of parameterssuch as white-to-white (W-W) or corneal thicknesswith the aim of fine-tuning postoperative outcomes, and the different eye biometers have evolved to newer swept-source optical coherence tomography (OCT) technology [9].

In this context, the goal of this study was to evaluate the symmetry of interocular biometric parameters in a large population, using a biometer endowed with swept-source technology.

\section{Materials and methods}

A total of 4090 patients-2546 female and 1544 male-were included in this study, recruited from the patients undergoing cataract surgery in the center and who met the inclusion criteria.

These patients underwent consecutive sweptsource optical biometry performed with an IOLMaster 700 (Carl Zeiss Meditec AG, Jena, Germany). The study followed the tenets of the Declaration of Helsinki and had been approved by the local ethics committee. The assessments took place between February 2014 and December 2018 at Miranza IOA Madrid. The inclusion criteria limited the eligible subject population to phakic patients with no history of ocular surgery or eye trauma. Contact lens wearers had to stop using them at least 15 days before the assessment and after discarding corneal warpage with a new topography.

All measurements were taken before instilling mydriatic eye drops and before measuring intraocular pressure with contact tonometry, to avoid any ocular surface irregularities that could arise secondary to these procedures. Three measurements per eye are obtained by the same operator for each subject when a biometry is performed. The measurements were taken by two of the authors (ELA and NG). The biometric parameters that were evaluated were those that have been included in various IOL power calculation formulas, including: axial length (AL), mean anterior curvature (Rm), anterior chamber depth (ACD), crystalline lens thickness (LT), central corneal thickness (CCT) and white-to-white (WTW). Moreover, the Chang-Waring chord distance (CWC-D) and the Chang-Waring chord angle (CWC-A) were also evaluated. The CWC-D or chord length $\mu$ is the displacement (distance) between the subject-fixated coaxially sighted corneal light reflex and the pupil center, while CWC-A is the orientation (angle) of that displacement (e.g., Chord $\mu$ : 0.35 mm @ 55 ${ }^{\circ}$ ) [10]. The quality of each measurement was assessed before performing the data analysis, and those eyes that had raised "warning" or "failed" alerts for any of the biometric parameters under assessment were completely excluded from the analysis.

\section{Statistical analysis}

A descriptive and comparative analysis between both eyes was carried out focusing on the above-mentioned biometric parameters. The comparative analysis was carried out by means of either the Student's $t$-test for paired samples or the Wilcoxon test depending on whether or not the variables met the criteria for normality (assessed by the Shapiro-Wilk test). Furthermore, the intraclass correlation coefficient (ICC) was also analyzed. Aside from the numerical analysis, Bland-Altman graphs were also plotted for each parameter. Moreover, concordance between both eyes was studied analytically using the Passing-Bablok regression to ascertain whether or not left- and righteye measurements are interchangeable.

Given the vector nature of the $\mathrm{CWC}$-involving a magnitude (CWC-D) and an orientation (CWC-A) this variable was decomposed into its vertical $[y=$ CWC-D*sine(CWC-A)] and horizontal $[x=$ CWC$\mathrm{D} * \operatorname{cosine}(\mathrm{CWC}-\mathrm{A})]$ components to facilitate the statistical analysis.

Differences were considered statistically significant if the corresponding $p$-value $<0.05$.

\section{Results}

A total of 4090 patients with a mean age of $67.45 \pm 16.69$ years (range: 5 to 99 ) were included in the present study. Among them, $62.2 \%$ were female with a mean age of $67.76 \pm 16.13$ years (range: 5 to 99) and $37.8 \%$ were male with a mean age of $66.32 \pm 17.55$ years (range: 8 to 97 ). Table 1 shows the mean and median values obtained in each eye for 


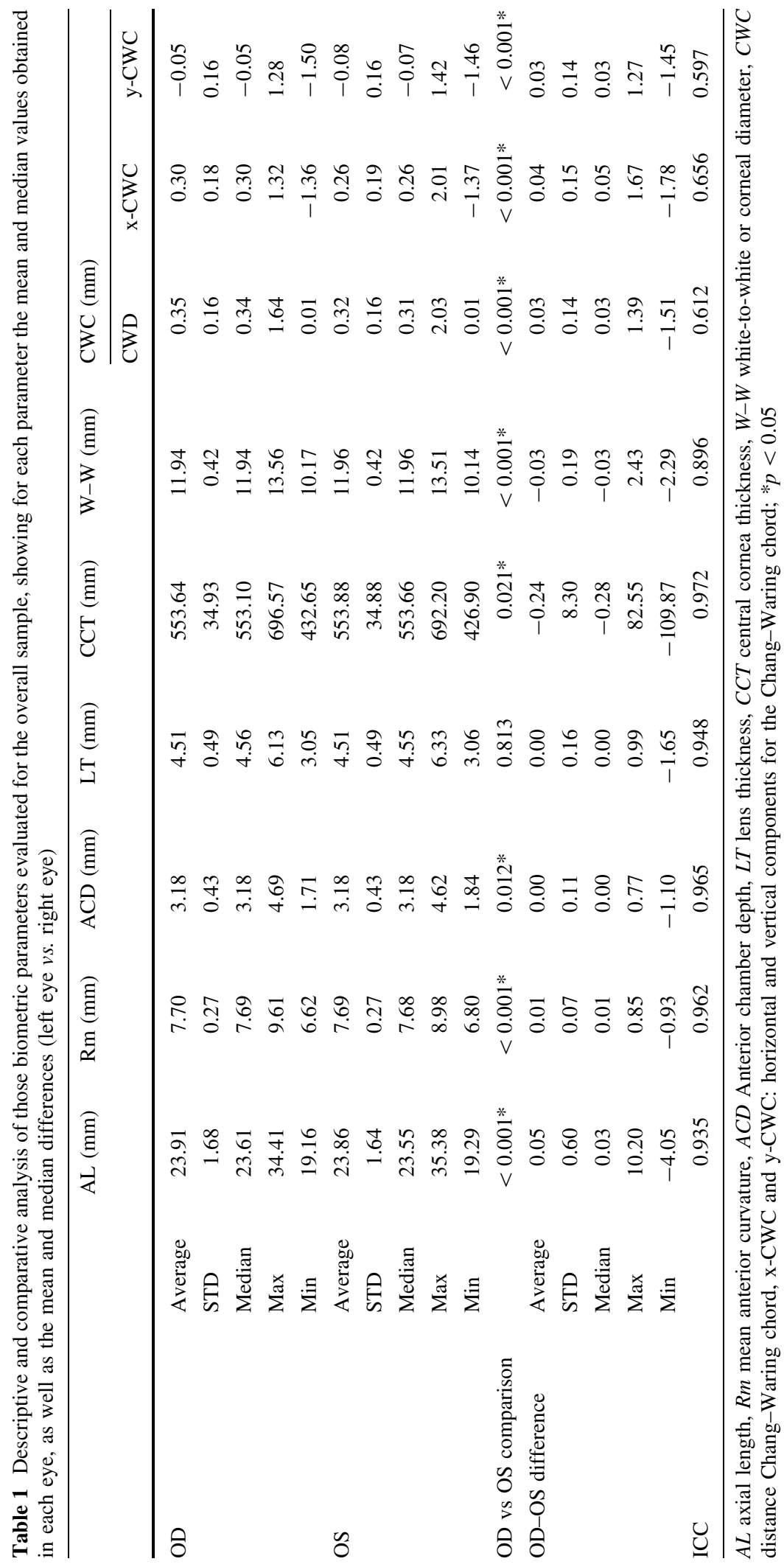


each parameter and the mean and median differences (left eye $v s$. right eye) for better visualization of the magnitudes.

ICC results are also included in Table 1, revealing an excellent correlation between the right eye and the left eye for almost all the biometric parameters under study (ICCs $>0.89$ ) with the exception of the CWC, considering both its magnitude (CWC-D) and its vertical (y-CWC) and horizontal (x-CWC) components, which showed moderate correlation values $(\mathrm{ICC}=0.612, \quad$ ICC $=0.656 \quad$ and $\quad$ ICC $=0.597)$ $[11,12]$.

When breaking the data down by gender, the results show a similar trend to that of the overall sample, as given in Table 2.

Figure 1 shows the Bland-Altman graphs corresponding to each biometric parameter under study. Mean differences OD-OS close to zero were obtained for all parameters. Limits of agreement for differences OD-OS for each variable are plotted in Fig. 1. The width of those limits of agreement around the mean value was $2.34 \mathrm{~mm}$ for $\mathrm{AL}, 0.28 \mathrm{~mm}$ for $\mathrm{Rm}$, $0.45 \mathrm{~mm}$ for ACD, $0.62 \mathrm{~mm}$ for $\mathrm{LT}, 32.54 \mu \mathrm{m}$ for CCT and $0.74 \mathrm{~mm}$ for WTW.

Bland-Altman plots revealed relevant differences only for AL, as shown in Fig. 1, with a width of more than $2 \mathrm{~mm}$ for the limits of agreement around the mean (OD-OS) value. The dispersion of differences in AL data shown in Fig. 1 appears to be concentrated in average ALs above $24 \mathrm{~mm}$. If the sample for AL is broken into two groups $(\mathrm{AL}<24 \mathrm{~mm}$ and $\mathrm{AL} \geq 24$

Table 2 The intraclass correlation coefficient (ICC) for female and male for the biometric parameters analyzed

\begin{tabular}{lll}
\hline & \multicolumn{1}{l}{ ICC } & \\
\cline { 2 - 3 } & Female & Male \\
\hline AL (mm) & 0.924 & 0.948 \\
Rm (D) & 0.963 & 0.96 \\
ACD (mm) & 0.964 & 0.952 \\
LT (mm) & 0.948 & 0.947 \\
CCT (mm) & 0.974 & 0.968 \\
WTW (mm) & 0.898 & 0.884 \\
CWC-D (mm) & 0.626 & 0.588 \\
\hline
\end{tabular}

$A L$ axial length, $R m$ mean anterior curvature, $A C D$ anterior chamber depth, $L T$ lens thickness, $C C T$ central cornea thickness, WTW white-to-white or corneal diameter, $C W C$ distance Chang-Waring chord $\mathrm{mm}$ ) and the Bland-Altman analysis is repeated, limits of agreement for the $\mathrm{AL}<24 \mathrm{~mm}$ group narrow to $0.94 \mathrm{~mm}$, whereas in the $\mathrm{AL} \geq 24 \mathrm{~mm}$ group the width of the limits of agreement is $2.90 \mathrm{~mm}$, as shown in Fig. 2. Axis scaling in Fig. 1 for AL is maintained in Fig. 2 for better visualization of the differences in the width of the limits of agreement.

Table 3 shows the results of the Passing-Bablok regression. The linearity of the OD- $v s$-OS relationship can be correctly assumed for all parameters (Cusum test: $p>0.05$ in all cases). Confidence intervals were obtained for the slope containing the unit value, while the confidence interval for "intercept" contains the zero value for all parameters except for WTW and CWC.

The Chang-Waring chord (CWC) analysis was performed separately from the rest of the parameters due to its vector nature. Values obtained for both eyes are shown in Fig. 3, which is a polar-coordinate plot, where the specular symmetry between left and right eyes can be seen. In order to statistically evaluate the potential differences between left and right eyes, CWC values (distance and angle) were converted into their corresponding $x$ and $y$ Cartesian components. Then, aiming to remove the effect of specular symmetry, we reversed the sign of the $x$-coordinate value for all the right eyes, thus obtaining the results shown in Fig. 4. Despite the nearly perfect symmetry that Figs. 3 and 4 seem to show, the statistical analysis reveals OD- $v s$ OS differences for the CWC's $x$ and $y$ components ( $p<0.001$ for both coordinates).

\section{Discussion}

The results of the present study confirm that our 4090 patient population show excellent ocular symmetry in terms of Rm, ACD, LT, CCT and W-W, as well as moderate ocular symmetry for CWC-D, as assessed by means of the swept-source optical biometry system IOLMaster 700 (Carl Zeiss Meditec AG, Jena, Germany). AL showed good agreement for eyes shorter than $24 \mathrm{~mm}$ and only moderate agreement for larger eyes.

There is some controversy regarding the impact of the interocular (i.e., left- $v s$-right) differences shown by certain parameters-such as AL and corneal power-upon postoperative refractive outcomes $[13,14]$. Different studies have tackled bilateral 

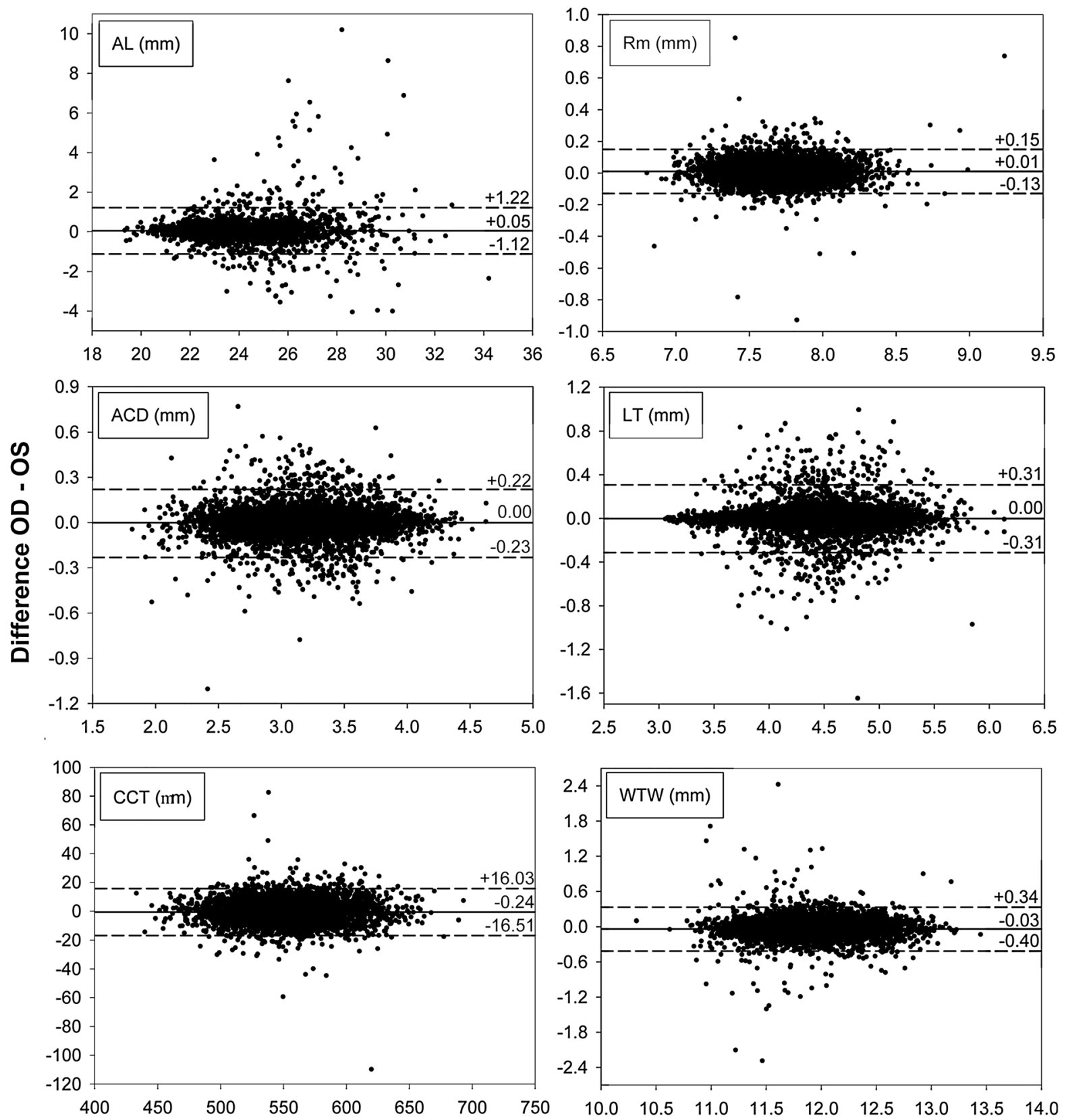

\section{Average OD and OS}

Fig. 1 Bland-Altman graphs corresponding to each biometric parameter under study. The horizontal dashed lines represent the limits of agreement according to a 95\% confidence interval around the mean value (horizontal solid line). $A L$ axial length,

symmetry by using the IOLMaster 500 [14-18], Pentacam [15, 19-23] and Orbscan II biometers $[3,24]$ (among others), but we have not found any studies in the literature where bilateral symmetry had
$R m$ mean anterior curvature, $A C D$ anterior chamber depth, $L T$ lens thickness, $C C T$ central cornea thickness, $W T W$ white-towhite or corneal diameter

been assessed by means of the swept-source optical biometric system that the IOLMaster 700 biometer includes. 
All biometric parameters analyzed in our study, except LT, showed interocular differences with corresponding $p$-value $<0.05$. However, we should not focus solely on statistical significance, but we must also assess whether or not those differences are clinically relevant. In this regard, it is important to consider also the ICC analysis, the Passing-Bablok regression and the Bland-Altman analysis, all of which help to draw more robust conclusions regarding the bilateral symmetry of the biometric parameters under study. It is also important to consider the repeatability and the reproducibility of the measurements [9].
Fig. 2 Bland-Altman graphs for the interocular difference in axial length (AL) for subjects with eyes shorter than $24 \mathrm{~mm}$ (top) and for eyes larger than $24 \mathrm{~mm}$ (bottom). The horizontal dashed lines represent the limits of agreement according to a 95\% confidence interval around the mean value (horizontal solid line)

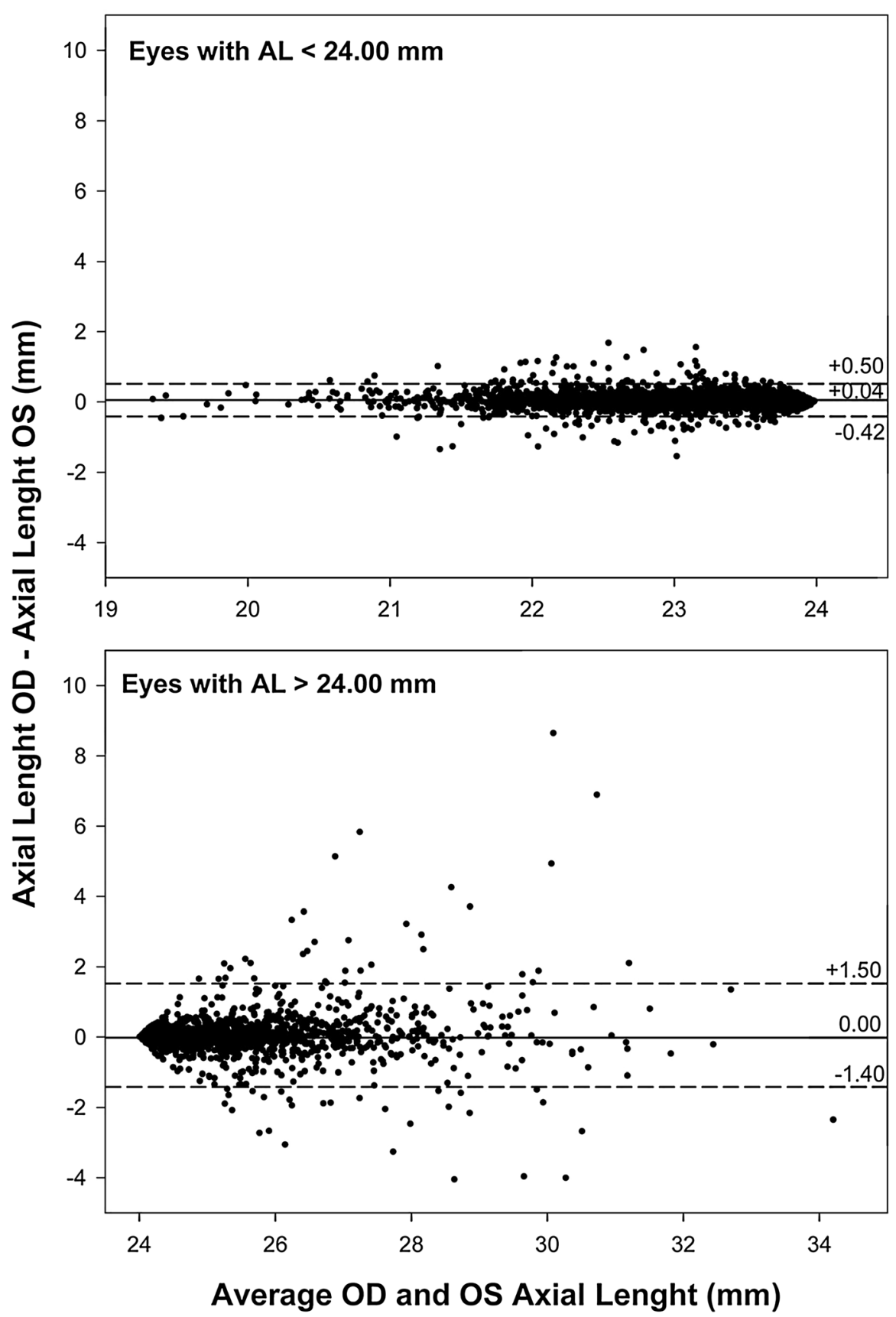


Table 3 Results of the Passing-Bablok regression comparing values obtained between right and left eye for every parameter

\begin{tabular}{|c|c|c|c|c|c|c|}
\hline \multirow[b]{2}{*}{ AL } & \multirow{2}{*}{$\begin{array}{l}\text { Regression equation } \\
\mathrm{OD}=0.0990+0.9971 \mathrm{OS}\end{array}$} & \multicolumn{2}{|c|}{$95 \%$ CI for intercept } & \multicolumn{2}{|c|}{$95 \%$ CI for slope } & \multirow{2}{*}{$\frac{\mathrm{CTL}}{p=0.99}$} \\
\hline & & -0.0370 & 0.2340 & 0.9914 & 1.0029 & \\
\hline $\mathrm{Rm}$ & $\mathrm{OD}=0.0457+0.9951 \mathrm{OS}$ & -0.0133 & 0.1040 & 0.9875 & 1.0028 & $p=0.32$ \\
\hline $\mathrm{ACD}$ & $\mathrm{OD}=-0.0168+1.0044 \mathrm{OS}$ & -0.0370 & 0.0033 & 0.9981 & 1.0107 & $p=0.42$ \\
\hline LT & $\mathrm{OD}=-0.0111+1.0027 \mathrm{OS}$ & -0.0351 & 0.0123 & 0.9973 & 1.0081 & $p=0.52$ \\
\hline CCT & $\mathrm{OD}=-1.3743+1.0020 \mathrm{OS}$ & -5.2811 & 2.4463 & 0.9950 & 1.0090 & $p=0.62$ \\
\hline WTW & $\mathrm{OD}=-0.1561+1.0108 \mathrm{OS}$ & -0.2913 & -0.0233 & 0.9997 & 1.0220 & $p=0.25$ \\
\hline $\mathrm{x}-\mathrm{CWC}$ & $\mathrm{OD}=0.0452+0.9994 \mathrm{OS}$ & 0.0392 & 0.0508 & 0.9755 & 1.0238 & $p=0.80$ \\
\hline y-CWC & $\mathrm{OD}=0.0313+1.0020 \mathrm{OS}$ & 0.0293 & 0.0331 & 0.9731 & 1.0316 & $p=0.62$ \\
\hline
\end{tabular}

$A L$ axial length, $R m$ mean anterior curvature, $A C D$ anterior chamber depth, $L T$ lens thickness, $C C T$ central cornea thickness, $W-W$ white-to-white or corneal diameter, $x$-CWC and $y$-CWC horizontal and vertical components for the Chang-Waring chord, $C I$ confidence interval, $C T L$ Cusum test for linearity (linearity if $p>0.05$ )

\section{Axial length}

Axial length's bilateral symmetry was analyzed by $\mathrm{Li}$ et al., in 2014, in 397 subjects, using an A-scan ultrasound device (Compuscan UAB 1000, Storz Inc., St. Louis, MO). The study revealed an excellent correlation between both eyes ( $r=0.95$ ) [25]. Regarding studies using the IOLMaster 500 biometer, they have shown similar results to those of the present study, especially for eyes shorter than $24 \mathrm{~mm}$ : For instance, in a sample of 50 healthy subjects, mean interocular $\mathrm{AL}$ difference was as low as $0.01 \pm 0.32 \mathrm{~mm}$, showing a strong interocular AL correlation ( $r=0.96$ ) [26]. Hong et al. [17] also found bilateral symmetry in terms of AL when assessing a sample of 260 healthy subjects $(22.38 \pm 4.1$ years $)$. Mean interocular difference was $0.003 \pm 0.217 \mathrm{~mm}$ $(p=0.839)$. Another multicenter study encompassing 14,016 subjects also revealed interocular symmetry for $\mathrm{AL}$, with a mean difference of $0.06 \pm 0.40 \mathrm{~mm}$ [27]. Compared to the above-mentioned research studies, ours yielded a high interocular correlation for AL $(\mathrm{ICC}=0.935)$, while the Bland-Altman analysis (Fig. 1) showed $+1.22 \mathrm{~mm}$ and $-1.12 \mathrm{~mm}$ as upper and lower $95 \%$ limits around mean difference $(0.05 \pm 0.60 \mathrm{~mm})$. The Passing-Bablok regression analysis allows us to conclude the equivalence of the left-eye and right-eye AL values, with a better agreement for eyes shorter than $24 \mathrm{~mm}$, as shown in Fig. 2.

However, there are also some authors who did report bilateral asymmetry for $\mathrm{AL}$, for instance, Mahroo et al. [16], who assessed a sample of 4571 subjects $(75.9 \pm 9.4$ years $)$ with bilateral cataract and concluded that the right eyes were, on average, $0.05 \mathrm{~mm}$ longer than the left ones $(p<0.001)$. Although this $0.05-\mathrm{mm}$ difference has a significantly associated $p$-value, it cannot be considered clinically significant unless a proper correlation analysis is subsequently performed. For eyes having AL $>24.8$ $\mathrm{mm}$, more relevant interocular differences have been observed. Kansal et al. [14] reported a mean interocular difference of $0.36 \pm 0.41 \mathrm{~mm}$ for a sample of 389 myopic subjects, while the results for a sample of 202 subjects with high bilateral myopia showed bilateral symmetry, with mean AL for left and right eyes of $29.43 \pm 2.40 \mathrm{~mm}$ and $29.31 \pm 2.39 \mathrm{~mm}$, respectively $(p=0.587)$ [15].

Regarding the results obtained by Kansal et al. [14] for eyes with $\mathrm{AL}>24.8 \mathrm{~mm}$, our results show a trend to more interocular differences in AL for larger eyes. As shown in Fig. 1, the differences in AL for eyes shorter than $22 \mathrm{~mm}$ are insignificant, whereas larger differences appear for eyes larger than $24 \mathrm{~mm}$ (especially between 26 and $31 \mathrm{~mm}$ ).

In summary, no overall interocular differences have emerged from our study for axial length in eyes shorter than $24 \mathrm{~mm}$, and moderate differences have been found for eyes larger than $24 \mathrm{~mm}$. Nonetheless, according to Knox Cartwright et al.'s [27] conclusions, when left-to-right-eye AL difference exceeds $0.70 \mathrm{~mm}$ for a given subject, it is recommended to verify biometric data to minimize the likelihood of post-surgical refractive errors. 
Fig. 3 Polar coordinate diagram showing ChangWaring chord (CWC) values for both eyes (black figures for OD and white figures for $\mathrm{OS}$ ). $O D$ right eyes, $O S$ left eyes

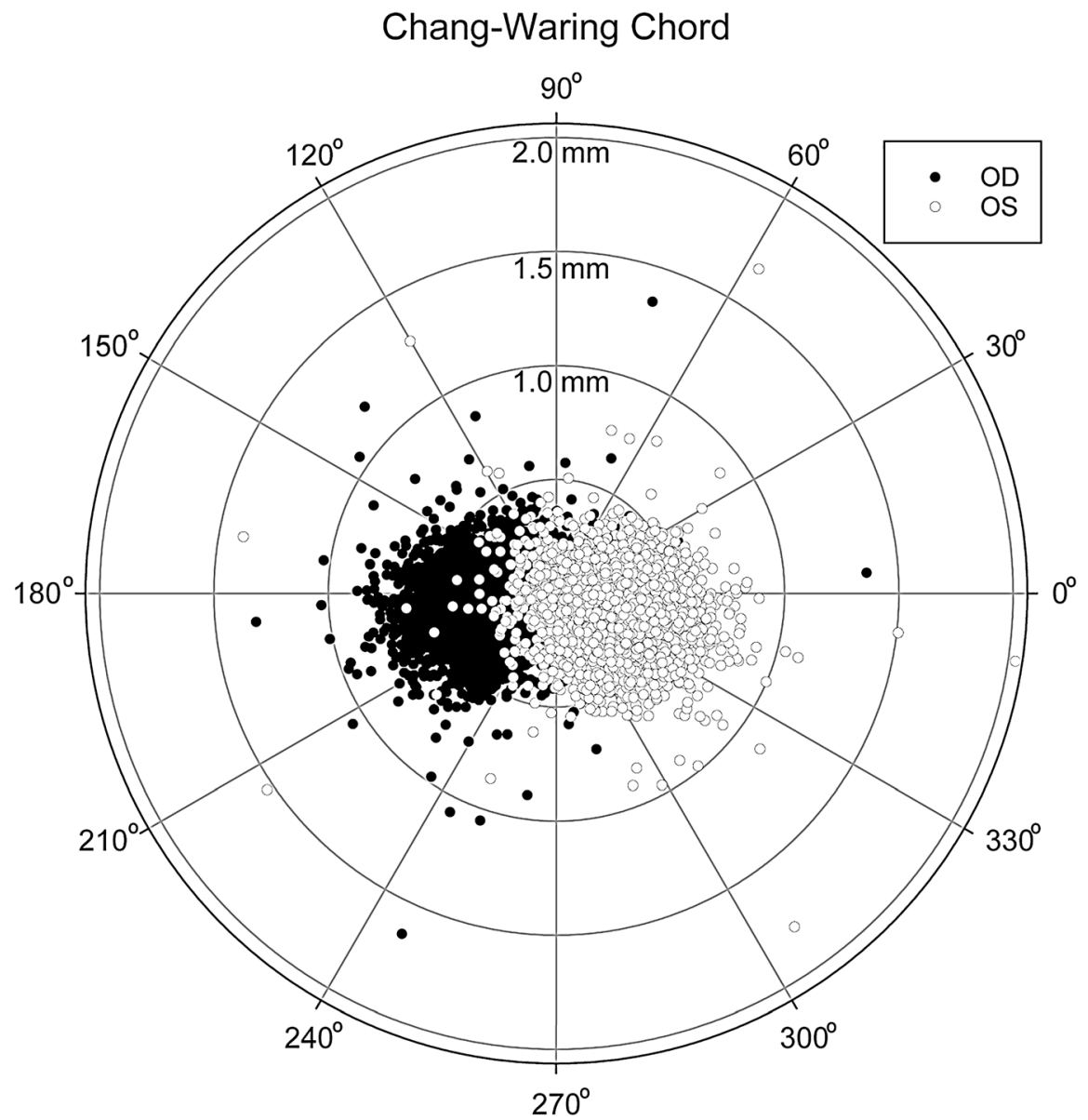

Mean anterior curvature $(\mathrm{Rm})$

The cornea provides approximately two-thirds of the eye's refractive power [28]. The interocular differences for the anterior corneal power have been studied by other authors and the vast majority of them observed symmetry for this biometric parameter using the Pentacam system. Li et al. [25] analyzed ocular symmetry in terms of anterior corneal curvature (D), finding a mean interocular difference of $0.00 \pm 0.24$ $\mathrm{D}(p=0.939)$ and a high correlation $(r=0.99)$. Dienes et al. [21] also studied ocular symmetry with the Pentacam system in 65 healthy subjects (mean age: $39.95 \pm 15.44$ years) and reported mean differences of $0.37 \pm 0.39 \mathrm{~mm}$ and $0.43 \pm 0.44 \mathrm{~mm}$ for the flat and steep meridians, respectively. A study by Naderan et al. [29] on 306 healthy eyes also found no interocular differences for mean anterior corneal power $(43.0 \pm 1.1 \mathrm{D}$ and $43.2 \pm 1.2 \mathrm{D}$ for right and left eyes, respectively $(p=0.325))$. Another multicenter study with interocular analysis of 14,016 subjects reported interocular symmetry with differences of $-0.07 \pm 0.49 \mathrm{~mm}$ [27].

Our results are in good agreement with those reported by the above-mentioned authors; moreover, considering the IOLMaster 700's repeatability and reproducibility features for keratometric radius $(0.02 \pm 0.06 \mathrm{~mm}$ and $0.02 \pm 0.07 \mathrm{~mm}$, respectively $)$ [9], we have found bilateral symmetry for Rm despite the fact that $p$-value $<0.05$. The Passing-Bablok analysis places the values 1 and 0 within the $95 \%$ confidence intervals for "slope" and "intercept," respectively, which means that equivalence can be assumed based on the Rm values obtained for left and right eyes. 
Fig. 4 Cartesian coordinate diagram showing CWC components for both eyes (black figures for OD and white figures for OS). For the right eyes (OD), the sign of the $\mathrm{x}$-coordinate has been reversed to remove the effect of specularity (bottom)

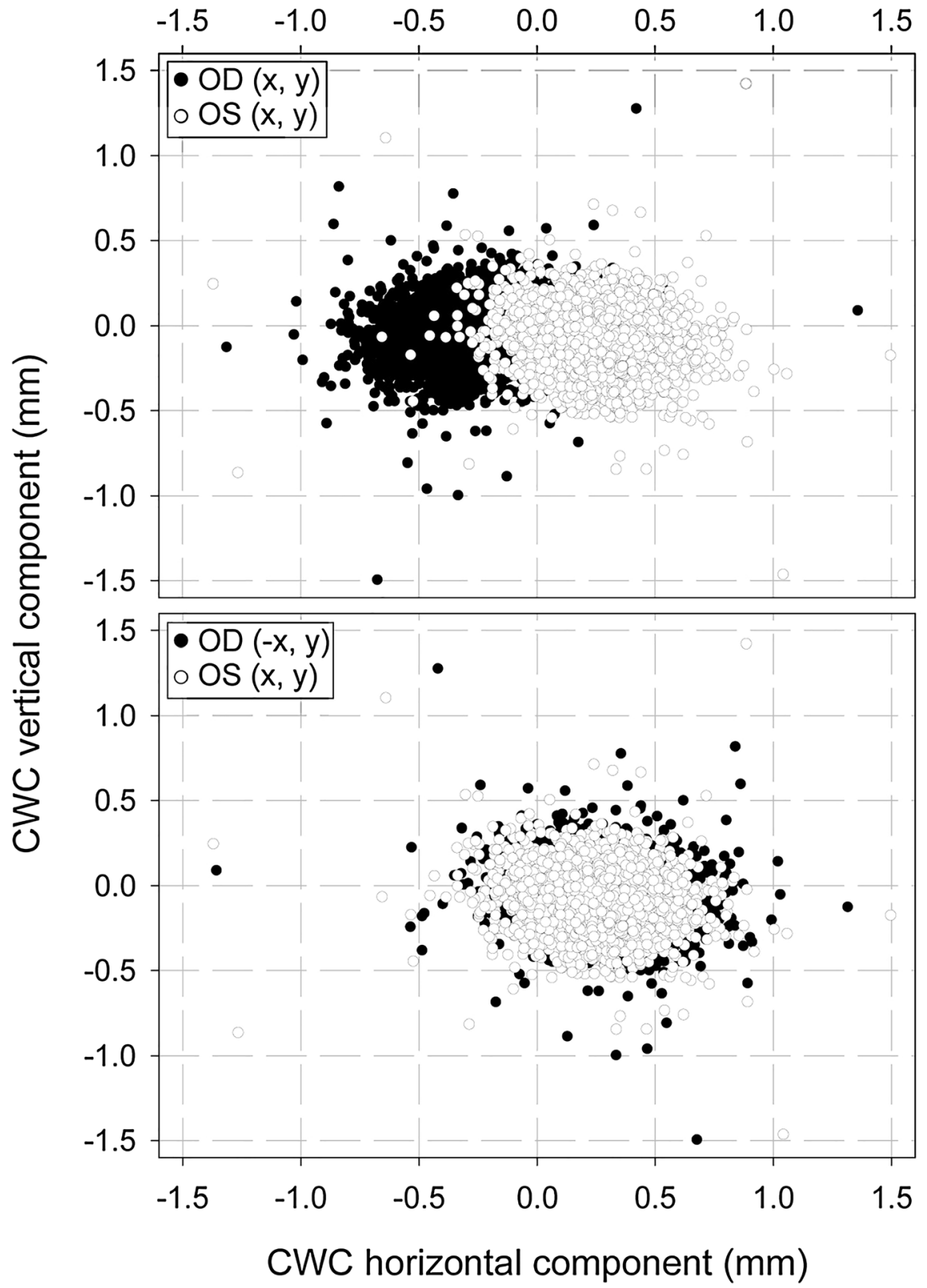

Anterior chamber depth (ACD)

ACD is another important IOL power calculation biometric parameter. Olsen et al. [30] reported refractive error rates as high as 42, 36 and 22\% resulting from mistakes when measuring $\mathrm{ACD}, \mathrm{AL}$ and corneal power, respectively.

Our results suggest there is bilateral symmetry for $\mathrm{ACD}$, despite the $p$-value being $<0.05$. Considering that the IOLMaster 700's repeatability and reproducibility features for ACD are $0.01 \pm 0.02 \mathrm{~mm}$ and $0.01 \pm 0.03 \mathrm{~mm}$, respectively [9], minor changes to those values cannot be considered to be relevant. The Passing-Bablok analysis places the values 1 and 0 within the $95 \%$ confidence intervals for "slope" and "intercept," respectively, which means that equivalence can be assumed based on the ACD values obtained for left and right eyes.

Other authors have also studied ACD's bilateral symmetry using different measuring devices. Li et al. 
[25] used an ultrasonic biometer (an A-scan ultrasound device [Compuscan UAB 1000, Storz Inc., St. Louis, MO]) in 397 subjects, and they found a mean interocular difference of $-0.01 \pm 0.15 \mathrm{~mm}$ with a high Pearson's correlation coefficient $(r=0.86)$. Palamar et al. [22] obtained a similar mean difference $(-0.03 \pm 0.07 \mathrm{~mm})$ using a different A-scan biometer model (Sonogage Eye Scan, Cleveland, OH, USA) in a population comprising 42 hyperopic subjects showing anisometropia (1 D mean spherical equivalent difference between eyes).

\section{Crystalline lens thickness (LT)}

This biometric parameter has been much less studied than AL, ACD and Rm. In the above-mentioned study on hyperopic eyes having anisometropia (1 D mean spherical equivalent difference between eyes), mean interocular difference for LT was $-0.09 \pm 0.40 \mathrm{~mm}$, their population sample being younger and smaller than our study's [22]. Moreover, these authors found no differences between eyes having different AL. (For their sample, mean interocular difference for AL was $-0.95 \pm 0.50 \mathrm{~mm}$.) Similarly, there are other authors that found no interocular differences for LT either $(-0.01 \pm 0.45 \mathrm{~mm})$, although in this case Pearson's correlation analysis revealed a weak correlation ( $r=0.37$ ) [25]. On the other hand, the results obtained in the present study-namely mean difference $(0.00 \pm 0.16 \mathrm{~mm})$, ICC (0.948) and Bland-Altman graphs-underpin interocular symmetry for lens thickness. The Passing-Bablok analysis places the values 1 and 0 within the $95 \%$ confidence intervals for "slope" and "intercept," respectively, which means that equivalence can be assumed based on the LT values obtained for right and left eyes.

\section{Central corneal thickness (CCT)}

Bilateral symmetry for CCT was confirmed in our study. Some studies in the literature have analyzed the interocular CCT difference using the Orbscan system, but most have relied on the Pentacam platform, which has a measurement variability of $0.51 \mu \mathrm{m}$, as reported by some authors [31]. Thus, Dienes et al. [21] and Henriquez et al. [23] studied ocular symmetry both in eyes with keratoconus and in healthy eyes. In Henriquez et al.'s [23] healthy-eye sample (53 subjects; mean age $28.4 \pm 5.3$ years), mean interocular difference was $10.28 \pm 7.89 \mu \mathrm{m}$, while in Dienes et al.'s [21] (65 subjects; mean age $39.95 \pm 15.44$ years), mean interocular difference was $5.59 \pm 4.90 \mu \mathrm{m}$, showing an excellent correlation between both eyes $(r=0.98)$. The study by $\mathrm{Li}$ et al. [19] produced the same correlation value ( $r=0.98)$ although with a smaller interocular difference $(0.51 \pm 6.79 \mu \mathrm{m})$. Falavarjani et al. [20], using a larger sample (275 subjects; mean age $29.1 \pm 7.73$ years), also obtained an excellent correlation $(r=0.90)$ with a mean interocular difference of $8.42 \mu \mathrm{m}$.

Durr et al. [24] studied interocular differences in 3835 subjects (a sample size similar to ours) with the Orbscan system, obtaining a mean difference for CCT of $0.28 \mu \mathrm{m}$, with ICC $=0.984$ [24]. Other authors who also relied on the same measuring platform found a mean interocular difference of $8 \pm 7 \mu \mathrm{m}$, with a high correlation $(r=0.95)$ [3]. In this context, our results resemble those obtained by Durr et al. [24] and Li et al. [25]: mean difference of $0.24 \mu \mathrm{m}$ and $\mathrm{ICC}=0.972$.

Chang-Waring chord distance (CWC-D) and Chang-Waring chord angle (CWC-A)

No studies have been found in the literature analyzing interocular differences for these two parameters (CWC-D and CWC-A). Our results have shown a mean interocular difference of $0.03 \pm 0.14 \mathrm{~mm}$ $(p<0.05)$ for CWC-D, with moderate interocular correlation. When the CWD vector is broken down into its horizontal and vertical components and these values are plotted in a graph, a quasi-perfect specular symmetry is observed (Figs. 3 and 4), although the statistical analysis did reveal differences between both eyes.

White-to-white distance (WTW)

Measuring the horizontal corneal diameter-the socalled white-to-white distance (WTW) - is required for cataract and refractive surgery and also for the diagnosis and characterization of certain corneal pathologies. Interocular differences for WTW have been studied using the Orbscan II system in a sample of 1001 subjects aged 18 to 45 years. Authors found no interocular differences $(p=0.26$ ), reporting mean WTW of $11.66 \pm 0.37 \mathrm{~mm}$ and $11.66 \pm 0.31 \mathrm{~mm}$ for right and left eyes, respectively [32]. In a sample of 
231 myopic subjects, no interocular differences were found either [2]. Our results are in line with the previous studies and confirm the bilateral symmetry for the WTW parameter. Despite the statistically significant differences, we can conclude that the difference of $0.03 \mathrm{~mm}$ between left and right eyes obtained in this study is not clinically relevant, taking into account that repeatability and reproducibility for this parameter amounts to $0.10 \pm 0.29$ and $0.13 \pm 0.35 \mathrm{~mm}$, respectively [9].

\section{Conclusions}

Analysis of our results in 4090 subjects leads us to conclude that there are no clinically significant interocular differences for the biometric parameters under study-AL, Rm, CD, LT, CCT, WTW and CWC-D—although for all of them, except the LT, statistically significant differences did arise. Regarding CWD, the results have revealed clinically significant differences although it must be said that they are related to enantiomorphism. In the case of $\mathrm{AL}$, moderate differences can be expected in eyes larger than $24 \mathrm{~mm}$.

In the event, for instance, of a cataract campaign in developing countries, if keratometry in one eye cannot be obtained, the other eye's value can be used. However, this strategy procedure must be carefully performed regarding axial length, especially in larger eyes.

The behavior for the overall sample was similar to the one observed after breaking the data down by gender.

\footnotetext{
Author contribution César Albarrán-Diego: was involved in conception and design of the work, analysis and interpretation of data for the work, revising it critically for important intellectual content and final approval of the version to be published. Nuria Garzón was involved in conception and design of the work, the acquisition, revising it critically for important intellectual content and final approval of the version to be published. Esther López-Artero was involved in the acquisition, analysis and interpretation of data for the work, drafting the work and final approval of the version to be published. Francisco Poyales was involved in conception and design of the work, drafting the work and final approval of the version to be published. María García-Montero was involved in conception and design of the work, drafting the work and final approval of the version to be published.
}

Funding Open Access funding provided thanks to the CRUECSIC agreement with Springer Nature.

\section{Declarations}

Conflict of interest The authors declare no financial interests in any of the products mentioned in this report.

Data availability Data can be requested from the Miranza R\&D Department (info.ioa@miranza.es).

Ethical approval The approval was obtained from the Hospital Clínico San Carlos, Madrid. C.P. BIO-2018.-C.I. 18/435-E. Date of approval: December 4, 2018.

Consent to Publish (Ethics) Patients signed informed consent regarding publishing their data.

Consent to participate Informed consent was obtained from all individual participants included in the study. It was approved by the EC.

Open Access This article is licensed under a Creative Commons Attribution 4.0 International License, which permits use, sharing, adaptation, distribution and reproduction in any medium or format, as long as you give appropriate credit to the original author(s) and the source, provide a link to the Creative Commons licence, and indicate if changes were made. The images or other third party material in this article are included in the article's Creative Commons licence, unless indicated otherwise in a credit line to the material. If material is not included in the article's Creative Commons licence and your intended use is not permitted by statutory regulation or exceeds the permitted use, you will need to obtain permission directly from the copyright holder. To view a copy of this licence, visit http://creativecommons.org/licenses/by/4.0/.

\section{References}

1. Wang L, Dai E, Koch DD, Nathoo A (2003) Optical aberrations of the human anterior cornea. J Cataract Refract Surg 29(8):1514-1521

2. Zha Y, Feng W, Han X, Cai J (2013) Evaluation of myopic corneal diameter with the Orbscan II topography system. Graefe's Arch Clin Exp Ophthalmol 251(2):537-541. https://doi.org/10.1007/s00417-012-2069-6

3. Myrowitz EH, Kouzis AC, O’Brien TP (2005) High interocular corneal symmetry in average simulated keratometry, central corneal thickness, and posterior elevation. Optometry Vis Sci Official Public Am Acad Optometry 82(5):428-431

4. Choi Y, Eom Y, Song JS, Kim HM (2017) Influence of corneal power on intraocular lens power of the second eye in the SRK/T formula in bilateral cataract surgery. BMC Ophthalmol 17(1):261. https://doi.org/10.1186/s12886017-0664-3

5. Jabbour J, Irwig L, Macaskill P, Hennessy MP (2006) Intraocular lens power in bilateral cataract surgery: whether 
adjusting for error of predicted refraction in the first eye improves prediction in the second eye. J Cataract Refract Surg 32(12):2091-2097. https://doi.org/10.1016/j.jcrs. 2006.08.030

6. Covert DJ, Henry CR, Koenig SB (2010) Intraocular lens power selection in the second eye of patients undergoing bilateral, sequential cataract extraction. Ophthalmology 117(1):49-54. https://doi.org/10.1016/j.ophtha.2009.06. 020

7. Aristodemou P, Knox Cartwright NE, Sparrow JM, Johnston RL (2011) First eye prediction error improves second eye refractive outcome results in 2129 patients after bilateral sequential cataract surgery. Ophthalmology 118(9):1701-1709. https://doi.org/10.1016/j.ophtha.2011. 05.010

8. Chiang PK, Hersh PS (1999) Comparing predictability between eyes after bilateral laser in situ keratomileusis: a theoretical analysis of simultaneous versus sequential procedures. Ophthalmology 106(9):1684-1691. https://doi.org/ 10.1016/S0161-6420(99)90390-1

9. Bullimore MA, Slade S, Yoo P, Otani T (2019) An evaluation of the IOLMaster 700. Eye Contact Lens 45(2):117-123. 0000000000000552

10. Chang DH, Waring GOt, (2014) The subject-fixated coaxially sighted corneal light reflex: a clinical marker for centration of refractive treatments and devices. Am J Ophthalmol 158(5):863-874. https://doi.org/10.1016/j.ajo. 2014.06.028

11. Bland JM, Altman DG (1996) Measurement error and correlation coefficients. BMJ 313(7048):41-42

12. Ludbrook J (2002) Statistical techniques for comparing measurers and methods of measurement: a critical review. Clin Exp Pharmacol Physiol 29(7):527-536. https://doi.org/ 10.1046/j.1440-1681.2002.03686.x

13. Rajan MS, Bunce C, Tuft S (2008) Interocular axial length difference and age-related cataract. J Cataract Refract Surg 34(1):76-79. https://doi.org/10.1016/j.jcrs.2007.08.023

14. Kansal V, Schlenker M, Ahmed IIK (2018) Interocular axial length and corneal power differences as predictors of postoperative refractive outcomes after cataract surgery. Ophthalmology 125(7):972-981. https://doi.org/10.1016/j. ophtha.2018.01.021

15. Zhu X, He W, Du Y, Zhang K, Lu Y (2019) Interocular symmetry of fixation, optic disc, and corneal astigmatism in bilateral high myopia: the shanghai high myopia study. Transl Vis Sci Technol 8(1):22. https://doi.org/10.1167/tvst. 8.1.22

16. Mahroo OA, Williams C, Hysi PG, Williams KM, Kailani O, Thompson J, Cumberland PM, Guggenheim JA, Rahi JS, Harrad RA, Hammond CJ (2015) Interocular asymmetries in axial length and refractive error in 4 cohorts. Ophthalmology 122(3):648-649. https://doi.org/10.1016/j.ophtha. 2014.10.021

17. Hong SW, Lee SB, Jee DH, Ahn MD (2015) Interocular retinal nerve fiber layer thickness difference in normal adults. PLoS ONE 10(2):e0116313. https://doi.org/10.1371/ journal.pone.0116313

18. Parssinen O, Kauppinen M, Halekoh U, Kaprio J, Rantanen $\mathrm{T}$ (2019) Heredity of interocular similarities in components of refraction: a population-based twin study among 66- to 79-year-old female twins. Acta Ophthalmol. https://doi.org/ 10.1111/aos.14033

19. Senthilkumari S, Talwar B, Dharmalingam K, Ravindran RD, Jayanthi R, Sundaresan P, Saravanan C, Young IS, Dangour AD, Fletcher AE (2014) Polymorphisms in sodium-dependent vitamin $\mathrm{C}$ transporter genes and plasma, aqueous humor and lens nucleus ascorbate concentrations in an ascorbate depleted setting. Exp Eye Res 124:24-30. https://doi.org/10.1016/j.exer.2014.04.022

20. Falavarjani KG, Modarres M, Joshaghani M, Azadi P, Afshar AE, Hodjat P (2010) Interocular differences of the Pentacam measurements in normal subjects. Clin Exp Optom 93(1):26-30. https://doi.org/10.1111/j.1444-0938. 2009.00446.x

21. Dienes L, Kranitz K, Juhasz E, Gyenes A, Takacs A, Mihaltz K, Nagy ZZ, Kovacs I (2014) Evaluation of intereye corneal asymmetry in patients with keratoconus. A Scheimpflug imaging study. PLoS ONE 9(10):e108882. https://doi.org/10.1371/journal.pone.0108882

22. Palamar M, Degirmenci C, Biler ED, Egrilmez S, Uretmen O, Yagci A (2016) Evaluation of the anatomic and refractive differences in hyperopic anisometropia. Int Ophthalmol 36(6):881-886. https://doi.org/10.1007/s10792-016-0199-2

23. Henriquez MA, Izquierdo L, Mannis MJ (2013) Intereye asymmetry detected by Scheimpflug imaging in subjects with normal corneas and keratoconus. Cornea 32(6):779-782. https://doi.org/10.1097/ICO. 0b013e31827b14ae

24. Durr GM, Auvinet E, Ong J, Meunier J, Brunette I (2015) Corneal shape, volume, and interocular symmetry: parameters to optimize the design of biosynthetic corneal substitutes. Invest Ophthalmol Vis Sci 56(8):4275-4282. https:// doi.org/10.1167/iovs. 15-16710

25. Li Y, Bao FJ (2014) Interocular symmetry analysis of bilateral eyes. J Med Eng Technol 38(4):179-187. https:// doi.org/10.3109/03091902.2014.899401

26. Chen FK, Yeoh J, Rahman W, Patel PJ, Tufail A, Da Cruz L (2012) Topographic variation and interocular symmetry of macular choroidal thickness using enhanced depth imaging optical coherence tomography. Invest Ophthalmol Vis Sci 53(2):975-985. https://doi.org/10.1167/iovs.11-8771

27. Knox Cartwright NE, Johnston RL, Jaycock PD, Tole DM, Sparrow JM (2010) The Cataract National Dataset electronic multicentre audit of 55567 operations: when should IOLMaster biometric measurements be rechecked? Eye 24(5):894-900. https://doi.org/10.1038/eye.2009.196

28. DelMonte DW, Kim T (2011) Anatomy and physiology of the cornea. J Cataract Refract Surg 37(3):588-598. https:// doi.org/10.1016/j.jcrs.2010.12.037

29. Naderan M, Rajabi MT, Zarrinbakhsh P (2017) Intereye asymmetry in bilateral keratoconus, keratoconus suspect and normal eyes and its relationship with disease severity. Br J Ophthalmol 101(11):1475-1482. https://doi.org/10. 1136/bjophthalmol-2016-309841

30. Olsen T (2007) Calculation of intraocular lens power: a review. Acta Ophthalmol Scand 85(5):472-485. https://doi. org/10.1111/j.1600-0420.2007.00879.x

31. Chen D, Lam AK (2007) Intrasession and intersession repeatability of the Pentacam system on posterior corneal assessment in the normal human eye. J Cataract Refract 
Surg 33(3):448-454. https://doi.org/10.1016/j.jcrs.2006.11. 008

32. Gharaee H, Abrishami M, Shafiee M, Ehsaei A (2014) White-to-white corneal diameter: normal values in healthy Iranian population obtained with the Orbscan II. Int $\mathbf{J}$ Ophthalmol 7(2):309-312. https://doi.org/10.3980/j.issn. 2222-3959.2014.02.20
Publisher's Note Springer Nature remains neutral with regard to jurisdictional claims in published maps and institutional affiliations. 